\title{
La marca bancaria: un ejemplo de cómo se administra el Capital de Relación
}

Agrivalca R. Canelón S.

- Magíster en Comunicación Social, mención Comunicación Organizacional, por por la Universidad Católica Andrés Bello (UCAB), Caracas, Venezuela

- Licenciada en Comunicación Social, mención Impreso, por la UCAB

- Docente del Postgrado de Comunicación Social de la UCAB, además de la cátedra de Teoría y Modelos de la Comunicación Estratégica del Programa de Estudios Técnicos Avanzados para TSU en Medios y Comunicaciones Estratégicas de la UCAB

- Miembro del Consejo de Redacción de la revista Comunicación. Estudios Venezolanos de la Comunicación, editada por la Fundación Centro Gumilla

- Colabora con la revista Debates IESA, del Instituto de Altos Estudios de Administración

- Cuenta con doce años de experiencia en el área de Comunicaciones Corporativas. Actualmente, se desempeña como Coordinadora de Consejos Editoriales del diario El Nacional

- acanelon@gmail.com 


\section{Resumo}

No setor de serviços, a marca expande seus limites, conjugando proximidade emocional, identificação com valores e relacionamento com o cliente com vistas à rentabilidade. Dessa maneira, percepção e execução se retroalimentam em um ciclo estratégico contínuo, sendo o setor bancário um de seus beneficiários mais emblemáticos.

PALAVRAS-CHAVE: MARCA • REPUTAÇÃO • SERVIÇOS • BANCOS

\section{Abstract}

In the services segment, the brand expands its limits, combining emotional closeness, identification with values and relationship with the client, aiming at profitability. In this way, perception and execution provide each other with feedback, where the banking sector is one of the most emblematic beneficiaries.

KEYWORDS: BRAND・REPUTATION • SERVICES • BANKS

\section{Resumen}

En el sector servicios, la marca expande sus límites, al conjugar la proximidad emocional, la identificación con valores y la relación con el cliente para aumentar la rentabilidad. De este modo, la percepción y la ejecución se retroalimentan, en un ciclo estratégico continuo, del cual el sector bancario es uno de los beneficiarios más emblemáticos.

PALABRAS CLAVE: MARCA • REPUTACIÓN • SERVICIOS • BANCA 


\section{Aperturar la cuenta}

El presente artículo tiene por objeto entablar una disertación teórica alrededor del Epoder comunicacional de la marca en tanto pilar desde donde diseñar, estructurar y conducir la experiencia de relación con el cliente más allá de la simple y puntual transacción de venta.

A tales fines, para ilustrar la argumentación se alude al sistema financiero, uno de los sectores en el que la naturaleza "híbrida" de sus productos (con un fuerte componente de servicios cuando de su entrega se trata), pone de relieve la ineludible articulación entre los conceptos de la cultura, la identidad y la reputación organizacionales, al amparo de una publicidad signada por el reto de "retratar" y "connotar" una promesa intangible.

Para lograr el cometido explicativo, el texto ha sido divido en tres partes. En la primera se hace una breve incursión por la noción de la marca, su gestión en el marco específico del mercadeo de los servicios y las características de su comunicación publicitaria.

Este preámbulo sirve de pie al segundo apartado, en el que se expone una radiografía de las estrategias de comunicación y reputación de marca aplicadas por las principales entidades financieras en Venezuela, con asidero en aproximaciones realizadas por distintos investigadores. Entre los hallazgos destaca la preferencia de los bancos por diferenciarse a través de una publicidad de imagen (emocional/alegórica), sin abandonar los atributos de eficiencia (servicio) y rendimiento (producto), aunque acompañados por los valores en ascenso de la Responsabilidad Social Corporativa y los cambios de identidad gráfica.

Por último, se deja nota de unas breves reflexiones finales, enraizadas en la importancia de asumir un trabajo multidisciplinario para una comunicación exitosa de la marca financiera.

\section{Reputación: ¿crédito sin vencimiento?}

Las preferencias de los consumidores pueden obedecer a muy distintas razones, desde una larga tradición pasando por el conocimiento y la confianza inspirada por el producto, el atractivo de la oferta o el brillo de una marca.

Según David Ogilvy (1967), una marca humaniza y personaliza a un producto/servicio, engatillando una conexión emocional o experiencia memorable del consumidor con el objeto. A la luz de esta afirmación, bien podría deducirse que la competencia se dirime en el dominio del imaginario: ser percibido y posicionarse en la mente del cliente, con una identidad de marca fuerte y diferencial, se convierte en la máxima del marketing. 
La marca se plantea, entonces, como un esfuerzo de gestión estratégica, continuo y coherente, que integra todos los procedimientos, los medios, las manifestaciones y las oportunidades de comunicación de la empresa; en suma, sus "modos de hacer" y sus "maneras de decir", desde la simple respuesta en un call center hasta el tiempo de entrega de la mercancía y el servicio postventa.

En consecuencia, la marca constituye un "mediador" en la relación de la organización con sus públicos (internos y externos), apalancada en una propuesta de valor: no es lo mismo "vender computadoras" que "vender soluciones de tecnología", suscribiendo las palabras del Prof. Marcelo Manucci (2005).

De suyo, más allá de la planificación estética y de diseño gráfico, el branding se centra en la cultura de la organización. Sobre la base de ésta se sigue un proceso en el que el nombre corporativo, la reputación y la equidad de la marca lucen superpuestos, amparando la idea de la venta como el primer acto sustancial para la sucesión de relaciones entre la compañía y sus clientes (ALLOZA, 2002).

Así las cosas, la comunicación integral de la organización se aviene esencial de cara al reforzamiento de las cualidades intangibles de la marca recreadas por los empleados e inscritas en la calidad del servicio prestado a través del "corredor de puntos de contacto", en cuyo camino la brecha entre las expectativas y las experiencias denota la diferencia (MEYER y SCHWAGER, 2007, p. 92).

En efecto, una comunicación óptima parte del "deber ser" de que el cliente sienta que es atendido y que su mensaje es comprendido por alguien que va a apoyarlo, ya sea que desee informarse, comprar o presentar un reclamo (PARRA, 2005).

Sin embargo, con frecuencia el excesivo foco en los productos le impide a las empresas aglutinar sus esfuerzos de marketing en torno a un esquema conceptual distinto, obviando que las relaciones con los clientes activan diálogos mediante los cuales pueden obtenerse insumos valiosos para modificar la conducta organizacional.

De acuerdo con Auletta (2000), existen cinco grados de implicación de la marca con la clientela:

- Conciencia: el consumidor se forma una percepción de la marca.

- Identidad: la comunicación fortalece la proposición de valor de la marca con asociaciones positivas.

- Relación: la empresa ofrece premios y el cliente responde con lealtad.

- Comunidad: el usuario desarrolla sentimientos de pertenencia.

- Apostolado: el cliente se convierte en un promotor de la marca.

Vista así, una relación duradera y profunda con la marca encarna más que una suma inconexa de interacciones, derivándose la rentabilidad a partir del historial de los contactos con el cliente, quien debe percibir que el tiempo dedicado a su persona, independientemente del medio utilizado, redunda en mayor conveniencia y beneficios (FERNÁNDEZ y FRIEDMANN, 2006, p. 56). 
Justo es acotar que la relación con el cliente ocurre independientemente de lo que la empresa haga y, aunque puede nacer en forma espontánea, no significa que esté exenta de diseño, gestión y monitoreo. En tal sentido, los sistemas de CRM han permitido un avance mayúsculo, incrementando la eficiencia-eficacia en términos de atención oportuna y personalizada con un costo unitario menor. No obstante, en ocasiones las posibilidades de la tecnología se han reducido a la simple administración de bases de datos.

Otro flanco supone la proyección del dominio de la marca fuera de la experiencia directa. Y es que detrás de todo cliente existe una madeja de relaciones, vale decir, se impone un proceso de "referenciación" cuya influencia se extiende merced el "boca a boca" o word of mouth, atenido a su propia lógica.

De por sí, la actividad de los servicios reviste una dinámica singular signada por la ejecución de personas, más todavía si se habla de la banca. En este orden, la gestión de la comunicación de la propuesta de valor exige el despliegue de mensajes que no omitan información, pero que tampoco exageren la promesa, so pena crear insatisfacción posterior.

Siguiendo las recomendaciones de Hill y Gandhi (1992), enmarcadas para el propósito de este artículo en el rubro financiero, el reto del mercadeo y la publicidad de servicios entraña:

- Incorporar al anuncio pruebas físicas (materialización de la idea de un banco o sus productos - ambientes de oficinas, sucursales, tarjetas de crédito, libretas de ahorro). Es importante cuidar de las instalaciones que va a ver el público, al igual que de la señalización.

- Apelar a símbolos que ayuden a entender el mensaje (conceptos de fortaleza -tranvía; felicidad - pareja de esposos; alegría - niños que ríen).

- Capitalizar sobre el rumor para aumentar la confianza (personificaciones).

- Representar al proveedor y al cliente (caracterización de situaciones y acciones - tarjetas de crédito o débito deslizadas en el punto de venta), aparte del contexto físico y social (dramatización - fiesta, personas que conversan, transacciones -, y documentación - pruebas de la calidad de los servicios ofrecidos).

En este ínterin, el valor conferido por los clientes al nombre, los símbolos y la personalidad de una marca financiera, endosados al valor proporcionado por los productos, los servicios y la empresa, minimizan tanto el riesgo percibido en la decisión de compra como la incertidumbre acerca de los resultados de uso (ESCOBAR, 2006).

En este sentido, a decir de Alloza (2002), en ningún otro sector como en el bancario es tan amplia y rica la entrega de la experiencia de marca a través de los empleados, así como el número y la diversidad de contactos con el cliente. 


\section{Experiencia bonificada: marcas bancarias en Venezuela}

De acuerdo con el criterio de algunos de los más destacados estudiosos de la publicidad contemporánea, en la actualidad la experiencia del producto resulta prácticamente inviable sin la mediación de la imagen de marca (CARO, 2006).

Tratándose del caso específico de los productos y los servicios financieros, éstos se ubican en una de las categorías más difíciles de publicitar en razón de que el mercado tiende a hacerse muy competitivo, a la vez que estrecha la diferenciación entre las carteras ofertadas por cada uno de los bancos (Acción Insight, 2003).

Ciertamente, la banca constituye uno de los sectores económicos más visibles para la generalidad de los consumidores debido a la fuerte actividad publicitaria que despliega, lo que en el caso de Venezuela le catapultó al primer lugar dentro del ranking de anunciantes para el año 2006 (Revista Producto, 2007).

Esta tendencia dentro del mercado publicitario se enmarca en la onda del crecimiento evidenciado por el rubro financiero durante los años 2005 y 2006, convirtiéndose en el más pujante de la economía venezolana gracias a los altos precios del barril petrolero y el incremento del gasto público. Estos factores, junto al control cambiario, han propiciado un aumento sostenido de la liquidez monetaria, aunque en medio de amplias regulaciones gubernamentales (OFICINA ECONÓMICA Y COMERCIAL DE ESPAÑA EN CARACAS, 2007, p. 9).

Desde el punto de vista del mercadeo y la comunicación este panorama ha supuesto para el sistema financiero venezolano un verdadero desafío, al tener que acoplarse al ritmo mundial de la industria, con foco sobre el mejoramiento de la experiencia del cliente.

Cítese en este apartado el informe Piecing the jigsaw (2005), elaborado por la red global PriceWaterhouseCoopers, según el cual el mix de productos bancarios, los incentivos al personal vinculados con la calidad y la satisfacción en la prestación del servicio, la cultura de alto desempeño y la propuesta de marca, deben respaldar una relación multifacética y duradera con el cliente.

Sin duda, el esfuerzo realizado por las empresas en aras de aminorar la distancia entre el "ser" y el "parecer" contribuyen a afianzar el valor de una marca a través del tiempo, al compás de una gestión estratégica de la comunicación que pasa necesariamente por la identidad organizacional y la construcción de una reputación avalada por los hechos.

Justamente, este planteamiento se hace más patente en el ámbito de los servicios, en particular en el caso del sector financiero en el que se adquiere una promesa de futuro (seguridad, bienestar) materializada en la tranquilidad del presente (reducción de la incertidumbre) (LÓPEZ, 2007). 
En la opinión de Justo Villafañe, una marca bancaria se granjea una buena reputación siempre y cuando responda a una tríada de valores, a saber:

- Funcionales: calidad, atención al cliente, confianza transmitida al público y percepción de liderazgo.

- Sociales: ética, comportamiento de la entidad, trato igualitario percibido por los clientes, Responsabilidad Social Corporativa, sensibilidad ecológica, apoyo a causas sociales.

- Emocionales: conocimiento de la empresa y su modo de trabajo, reconocimiento y simpatía que ésta genera entre sus clientes actuales y potenciales (Infoempleo.com, 2006).

A la luz de esta interpretación, el Informe Merco Marcas Financieras realizado para el año 2006 subraya el progresivo ascenso observado en los valores alusivos a la Responsabilidad Social Corporativa que, aunque ajenos a la naturaleza del negocio bancario, acrecientan la identificación de los usuarios/consumidores con las entidades del ramo, tradicionalmente ancladas en los atributos de la solvencia y la estabilidad.

A decir verdad, pareciera que en la última década la comunicación de los bancos ha dado un giro hacia el cultivo de una relación afectiva con el consumidor, afinando dos rutas con el ánimo de diferenciarse en el maremágnum del mercado: la calidad del servicio y los valores de la marca. Estas cualidades, en compañía de la ética y la Responsabilidad Social Corporativa, conectan con emociones que se alojan en la base del posicionamiento objetivo de cada institución financiera, al amparo de una publicidad más alegórica y menos descriptiva.

Siguiendo esta línea de argumentación, menciónese el estudio de Vallenilla (2005), a partir de los anuncios televisivos de las cinco primeras entidades bancarias venezolanas dentro del ranking de las captaciones del público para diciembre del año 2004: Banco de Venezuela/ Grupo Santander, Banesco, Banco Mercantil, Banco Provincial y Banco Occidental de Descuento. Conforme los hallazgos arrojados, en las comunicaciones evaluadas de estos bancos privó el uso de imágenes y símbolos por sobre el uso de pruebas físicas (promoción de un producto concreto).

Bajo esta óptica, se entrevé el fortalecimiento del filón intangible/emocional, con una "cúpula paraguas" y una personalidad definida de marca, las cuales cimentan la captación de nuevos clientes y la lealtad de los ya existentes, dejando en la retaguardia la exposición de los beneficios y la capacidad de respuesta en el servicio.

Menester es puntualizar, además, la agresiva avanzada protagonizada a partir de 2004 por las instituciones bancarias venezolanas grandes y medianas, en pos del consumo del ahorro, el crédito y las cuentas corrientes, apalancándose muchas en el cambio de sus rasgos de identidad visual, amén de la capitalización publicitaria de sus programas de Responsabilidad Social Corporativa.

Se perfila aquí con claridad una trayectoria que va del mensaje comercial orientado a crear una sólida imagen de marca, al mensaje social que apunta a gestar una fuerte 
imagen de empresa, la cual agrega valor al producto y a los procesos de mercadeo y de comercialización, con una ventaja sustentable en virtud de que remite a impresiones más estables y resistentes que los atributos particulares del bien o servicio.

A título ilustrativo, el estudio Entendiendo al Consumidor Venezolano (2007), elaborado por las firmas Urban \& Associates, Inc. y Datanalisis, señala que las entidades que se muestran con mayor fortaleza en Venezuela son Banco Mercantil, Banesco, Banco de Venezuela/Grupo Santander y Banco Provincial.

Si se complementa este dato con los antecedentes de la pesquisa Estudio sobre la percepción de notoriedad y reputación de las instituciones bancarias (2004), acometida por la compañía de investigación de mercados Ceninvest en la ciudad de Caracas, Banesco despunta ante los usuarios como el banco más próspero, prestigioso, responsable, innovador, moderno y con los servicios más eficientes. Por su parte, Banco de Venezuela/Grupo Santander se posiciona como una entidad conservadora y sólida, lo mismo que el Banco Mercantil; al cabo que el Banco Provincial es percibido como el más popular.

Para estos bancos el disponer de amplias cuotas de reputación implica, inevitablemente, retos importantes en materia de gerencia de las expectativas del público y cuidado de la imagen institucional.

Adquiere aquí fundamento la mirada del BBVA en cuanto a la gestión de su reputación corporativa, ubicándola al interior de la organización (visión) para proyectarla hacia el exterior con el comportamiento (cultura corporativa) y consolidarla en las relaciones con los stakeholders. Se revela, entonces, una alineación entre "lo que se dice" (comunicación) y "lo que se ofrece" (productos y servicios), en la búsqueda de un equilibrio óptimo de percepciones con realidad (RODRÍGUEZ, 2004).

En suma, de lo dicho hasta acá se desprende que el hacer técnico integrado al hacer cultural encuentra en la gerencia de la relación con el cliente una poderosa plataforma de comunicación desde donde moldear a la firma financiera como un todo, atendiendo a las líneas demarcadas por la dinámica de su mercado y sus capacidades.

\section{Conclusión: cerrar la operación}

En el sector financiero, el cliente establece contacto con la marca no tanto cuando se expone a la publicidad y las noticias, como cuando accede al sistema a través de los canales como el teléfono, los puntos de venta, los mailings, los call centers o los cajeros automáticos.

Siguiendo este planteo, la gerencia del ciclo del mercadeo relacional supone conjugar, a lo interno de la organización financiera, las fortalezas de equipos multidisciplinarios que trabajen en la complementariedad de productos y servicios, la satisfacción del cliente y una proposición de valor integradora. 
Tal vez los bancos grandes puedan permitirse la licencia de optar por una publicidad enfocada hacia la construcción de imagen, a diferencia de las entidades pequeñas, que se inclinan por una publicidad descriptiva de sus productos y servicios, presionadas por mostrar que pueden hacer lo mismo que sus pares más antiguas o de mayor escala.

Aunque hoy en día casi todos los productos llevan adherido algún tipo de servicio, la equidad de marca representa una ventaja inimitable según las particularidades y las condicionantes del sector de la economía en el que se inscribe. Así, los procesos de creación, afianzamiento o reposicionamiento de una marca están determinados por unos objetivos de negocio muy concretos, de tal modo que no pueden ser los mismos para un producto de gran consumo que para un servicio financiero.

Esta aseveración constituye apenas un aperitivo de los desafíos que supone mercadear, comunicar y promover servicios bancarios entre los consumidores/usuarios, toda vez que la publicidad tiene que convertir en tangible y palpable la "promesa del servicio", en aras de hacer deseable la oferta (GROVE y otros, 1997).

A ciencia cierta, sin identidad de marca no hay "gancho" de motivación "puertas adentro" de la organización, y tampoco fidelidad "puertas afuera” de ella. En últimas, para la banca, la marca es ante todo capital de relación.

\section{Referencias}

ACCIÓN Insight (2003). El modelo de compañía de servicio: una nueva estrategia para los bancos comerciales en microfinanzas. Disponível em: www.accionbogota.org/insight//S6A.pdf

ALLOZA, A. (2002). Integración de los intangibles estratégicos. XIII Congreso de Valores de Empresa y Sociedad. Disponível em: www.valor-lider.net/documents/02-B212AA.pdf

AULETTA, N. Mercadeo relacional: clientes para toda la vida. Debates IESA, V, (4), pp. 17-21, 2000.

CARO, A. Marca y publicidad: un matrimonio por amor. Trípodos, (18). pp. 9-21, 2006. Disponível em: www.tripodos.com/ pdf/18m_ACaro.pdf

CENINVEST. Estudio sobre la percepción de notoriedad y reputación de las instituciones bancarias. Papel de trabajo. 2004.

ESCOBAR, S. La equidad de marca "brand equity": una estrategia para crear y agregar valor. Estudios Gerenciales, (75), pp. 38 y 39, 2006. Disponível em: redalyc.uaemex.mx/redalyc/pdf/212/21207503.pdf

FERNÁNDEZ, P.; FRIEDMANN, R. No reste clientes, sume relaciones. Harvard Business Review. Edição América Latina, pp. 56-61 fev. de 2006.

GROVE, S. J., PICKETT, G. M. e STAFFORD, M. R. Addressing the advertising of services: a call to action. Journal of Advertising, (26), 1997.

HILL, D. J.; GANDHI, N. Services advertising: a framework to its effectiveness. The Journal of Services Marketing, (6), pp. 26$32,1992$.

Infoempleo.com. (2006). 'La Caixa' la marca con mejor reputación. Disponível em: www.merco.info/myfiles/pageposts/Merco_Marcas_Financieras_Infoempleo.pdf

LÓPEZ, I. Branding in South America. Conferencia INTA/ASIPI, 2007. Disponível em: www.ciac-international.com/docs/branding_south_america_061120_inigo.pdf

MANUCCI, M. Atrapados en el presente - la comunicación, una herramienta para construir el futuro corporativo. Quito, Ecuador: Editorial Quipus, Ciespal, 2005.

MEYER, C.; SCHWAGER, A. (2007, febrero). Comprendiendo la experiencia del cliente. Harvard Business Review. Edición América Latina, pp. 91-99, fev. de 2007.

OFICINA Económica y Comercial de España en Caracas. Informe Económico y Comercial Venezuela, pp. 6-36, jan. de 2007. 
Disponível em: www.oficinascomerciales.es/icex/cda/controller/pageOfecomes/0,5310,5280449_5296126_5287111 541516 VE, $00 . \mathrm{html}$

OGILVY, D. Confesiones de un publicitario. Barcelona, España: Oikos-Tau, 1967.

PARRA, D. Imagen de la empresa desde una perspectiva de calidad. Revista EAFIT, (105), 2005. Disponível em: http://web. archive.org/web/20021221235237/www.eafit.edu.co/revista/105/parra.html

PriceWaterhouseCoopers. Piecing the jigsaw: el futuro de los servicios financieros. Resumen Ejecutivo, 2005. Disponível em: www.pwc.com/extweb/pwcpublications.nsf/docid/54D2303E864F796B852570360063C52F/\$File/piecing_jigsaw_ esp.pdf

REVISTA PRODUCTO. Ranking de agencias 2007, maio de 2007. Disponível em: www.gep.com

RODRÍGUEZ, J. Percepción y medida en la reputación empresarial. Economía Industrial, (357), pp. 117-131, 2004. Disponível em: www.mityc.es/NR/rdonlyres/C4FCAB8E-08AC-4D54-A41C-6D82E254D08E/0/12_ManuelRodriguez_357.pdf

URBAN \& Associates, Inc. y Datanalisis, C.A. Entendiendo al consumidor venezolano - hábitos de consumo y el alcance de los medios. Investigación de Mercado, setembro de 2007.

VALLENILLA, R. ¿Cómo se hace tangible la promesa de un servicio? El caso de la banca. Debates IESA, X, (3), pp. 38-41, 2005. 